IMM 13-140

\title{
Are Knowledge Intensive Business Services Really Co-produced? Overcoming Lack of Customer Participation in KIBS
}

\author{
Juliana Bonomi Santos ${ }^{\mathrm{a}, \mathrm{b}}{ }^{1}$, Martin Spring ${ }^{\mathrm{c},}$ \\ ${ }^{a}$ Centro Universitário da FEI, Management Department, Rua Tamandaré, 688 - Liberdade, São \\ Paulo,01525-00, Brazil , +55(11)98493 0358, j.santos@fei.edu.br \\ ${ }^{b}$ Lancaster University, Lancaster University Management School,Management Science \\ Department, Bailrigg, Lancaster, Lancashire LA1 4YX, United Kingdom, \\ j.bonomisantos@lancaster.ac.uk \\ ${ }^{\mathrm{c}}$ Lancaster University, Lancaster University Management School,Management Science \\ Department, Bailrigg, Lancaster, Lancashire LA1 4YX, United Kingdom, +44 (0)1524 592739, \\ m.spring@lancaster.ac.uk
}

${ }^{1}$ Corresponding Author 
IMM 13-140

\section{Juliana Bonomi Santos}

Juliana Bonomi Santos is a Lecturer in Marketing Management and Competitiveness at Centro Universitário da FEI, Brazil, and an Honorary Research at Lancaster University Management School, where she also did her PhD. Her main research interests lie in the area of business relationships, service management and the operations of Knowledge Intensive Business Services and Professional Services.

\section{Martin Spring}

Martin Spring is a Professor in Operations Management at the Management Science Department of Lancaster University Management School. His research has contributed to prominent themes in Operations Management over the past twenty years. Most recently, his work has been in business service operations and business models. 
IMM 13-140

\section{RESEARCH HIGHLIGHTS}

- Providers adopt three strategies to compensate for limited customer participation in KIBS delivery processes

- The strategies are customer education, preventive and problem-management and are enabled by the expertise of KIBS employees

- Customer education requires more interaction with customers than the other two types of strategies

- The three strategies are used in a complementary way, depending on customers' ability and willingness to participate

- Despite the heterogeneity in customers' participation levels, providers' strategies enable the delivery of effective KIBS 
IMM 13-140

\begin{abstract}
Customer participation is considered necessary for the delivery of effective Knowledge Intensive Business Services (KIBS). However, for different reasons, KIBS customers are not always able to participate actively during the delivery process and providers have to compensate for this in order to deliver effective solutions. We conducted case-based research to understand how KIBS providers do this. The three cases studied suggest that, besides customer education, providers use preventive and problem-management strategies to counterbalance limited customer participation. These three strategies are used in a complementary way and are enabled by the expertise of KIBS providers. They also contribute to the delivery of effective KIBS. The research outcomes refine the existing knowledge of customer participation in KIBS, which has so far focused mainly on the causes and consequences of it and overlooked other related issues. Our results also suggest that practitioners could use the level of customers' ability and willingness to participate as segmentation criteria and then define their strategies and allocate their resources accordingly.
\end{abstract}

Keywords: Knowledge Intensive Business Services (KIBS); Customer Participation; Providers' Strategies; Providers' Expertise; Customer Education; Case Study. 
IMM 13-140

\section{Introduction}

Customers play an important role in the production of services and, thus, organizations providing service offerings must manage their customers' behaviour. Different aspects of this "participation" have already been explored in the literature (Etgar, 2008; Lengnick-Hall, 1996; Mills \& Morris, 1986; Yim, Chan, \& Lam, 2012). A number of studies show the benefits of having participative customers that comply with the instructions of providers (Dellande, Gilly, \& Graham, 2004), share information and other inputs, support decision-making (Yim et al., 2012) and offer constructive feedback (Bettencourt, 1997; Eisingerich, Auh, \& Merlo, 2013). Customer participation, it is argued, can positively influence service delivery effectiveness (Kelley, Donnelly, \& Skinner, 1990), customers' loyalty (Auh, Bell, McLeod, \& Shih, 2007) and satisfaction (Yim et al., 2012), sales performance (Eisingerich et al., 2013) and the value customers see in purchasing the service (Lapierre, 1997).

The participation of customers is particularly important in Knowledge Intensive Business Services (KIBS), in which providers deliver customized products and/or services to address customers' specific needs (Bettencourt, Ostrom, Brown, \& Roundtree, 2002). In defining service specifications in conjunction with providers (Nordin \& Kowalkowski, 2010; Selviaridis \& Spring, 2010), choosing among the alternative solutions (Aarikka-Stenroos \& Jaakkola, 2012), and helping solving potential complications during the service delivery, customers enable a smoother implementation of the offering (Bettencourt et al., 2002) and help to reduce the uncertainty inherent in these processes (Stewart, Hope, \& Muhlemann, 1998). They may also develop social bonds with service providers and, so, the relationship between the parties becomes more resilient and resistant to failures (Eisingerich et al., 2013).

However, many customers are not able or willing to actively engage in KIBS delivery processes. If customers lack expertise or role clarity, this can impede their engagement with the service delivery process (Aarikka-Stenroos \& Jaakkola, 2012; Bell \& Eisingerich, 2007; Bettencourt et 
al., 2002; Dellande et al., 2004). KIBS customers may also not get actively involved in the service delivery because they do not have the resources available to maintain a close interaction with providers (Töllner, Blut, \& Holzmüller, 2011). Additionally, customers that use KIBS providers to increment their capacity levels may show little motivation to participate (Skjølsvik, Løwendahl, Kvalshaugen, \& Fosstenløkken, 2007). The relationship between end-customers and providers can also be difficult to establish, if KIBS firms are hired by intermediaries (Jaakkola \& Hakanen, 2013).

Given the importance of customer participation for the effectiveness of KIBS delivery processes, managers must concern themselves with the management of less participative customers. Prior research has shown that strategies to educate and socialize customers can lead less expert and less motivated customers to become more involved in the service process (Auh et al., 2007; Büttgen, Schumann, \& Ates, 2012; Eisingerich \& Bell, 2006; Howcroft, Hamilton, \& Hewer, 2007). However, such efforts still require customers to interact with providers and are difficult to implement when customers show limited resource availability and limited willingness to cooperate. While existing studies have mainly focused on how to increase customer participation (Büttgen et al., 2012; Dellande et al., 2004; Eisingerich \& Bell, 2006), they have overlooked strategies that might be adopted to compensate for the lack of it.

A more comprehensive understanding of how KIBS providers deal with limited customer participation in the service delivery is, therefore, missing. To increase knowledge in this field, we investigated in detail the relationship between customers and providers during the delivery processes of three KIBS firms to answer the following questions: 1) How, if at all, do providers compensate for the lack of customer participation in KIBS delivery processes?; 2) How, if at all, do these efforts interrelate with customer education and socialization actions?; 3) How do providers' actions influence the effectiveness of the KIBS delivered? 
Our results show that, besides customer education actions, KIBS providers employ preventive and problem-management strategies. These strategies are less dependent on customers' inputs, enable providers to overcome the problems caused by limited customer participation and minimize the associated consequences of it. Ultimately, they lead to increased KIBS effectiveness, despite low levels of customer participation. The providers' expertise is a key enabler of preventive, problem-management and customer education actions, which are used in a complementary way depending on customers' willingness and ability to participate. As we show later, these research outcomes extend the current knowledge on customer participation in KIBS delivery processes and offer insights on how KIBS providers should segment and serve their customers. The paper is organized as follows. We first review the literature on customer participation in KIBS. The case study research design adopted is then presented. Next, we introduce the research outcomes, which are followed by a discussion. The final section contains the conclusion and suggestions for future research.

\section{Theoretical Background}

This section initially offers a definition of KIBS and presents the role of customer participation in these delivery processes. It then explores the outcomes and drivers of customer participation in KIBS.

\subsection{Customer Participation in Knowledge-Intensive Business Services (KIBS)}

KIBS are business-to-business services in which knowledge is used to develop customized products and/or services that solve customers' problems or address their specific needs (Bettencourt et al., 2002). According to Miles et al. (1995), both professional services, for example accountancy, and knowledge-intensive services aimed at developing and applying 
IMM 13-140

technologies, like integrated solutions (Nordin \& Kowalkowski, 2010), can be seen as KIBS. Two aspects of KIBS delivery processes have received extensive attention in the literature.

One is the fact that providers rely considerably on their employees' expertise to serve customers (Davenport, Jarvenpaa, \& Beers, 1996). Expertise encompasses the individuals' knowledge of specific domains (Amara, Landry, \& Doloreux, 2009), of customers' needs, characteristics and industries (Nätti \& Ojasalo, 2008) and of how to apply their knowledge to specific situations (Miles et al., 1995). It also involves individuals' abilities to easily access facts and understand how they interrelate, to solve problems based on assumptions, and to make fast and effective decisions (Dane, 2010).

The second aspect is the role of customer participation in KIBS delivery processes. Customer participation refers to customers' willingness to offer constructive feedback (Bettencourt, 1997; Eisingerich et al., 2013), comply with rules, follow providers' instructions (Dellande et al., 2004), provide inputs and make joint decisions during the service delivery (Yim et al., 2012). It thus differs from the widely diffused idea of co-production that focuses mainly on the supply of labour and other inputs to the service process (Etgar, 2008; Grönroos \& Ravald, 2011; LengnickHall, 1996; Mills \& Morris, 1986), and from the notion of value co-creation of the "service dominant logic" of Vargo and Lusch (2004), which refers to the influence of providers on customers' value-creation processes during the interaction between the parties (Grönroos \& Ravald, 2011; Jaakkola \& Hakanen, 2013; Vargo, 2008). Customer participation is seen as fundamental for the delivery of effective KIBS, as discussed next.

\subsection{Customer Participation and KIBS Effectiveness}

Although customer participation (Auh et al., 2007; Eisingerich \& Bell, 2006; Yim et al., 2012) is important for services in general, this is even more so in the KIBS context. Intensive customer 
IMM 13-140

participation increases the effectiveness of the KIBS delivered, that is the extent to which the solutions provided meet customers' needs (Tuli, Kohli, \& Bharadwaj, 2007) and are delivered on time without additional charges. In KIBS, the understanding of customers' problems and needs is often under-developed (Nordin \& Kowalkowski, 2010). In working closely with providers and sharing knowledge about their industries (Nätti \& Ojasalo, 2008), processes, operations (Tuli et al., 2007), preferences, and goals (Jaakkola \& Hakanen, 2013), customers contribute to the development of service specifications that accurately capture their needs. Providers can then be more certain about what customers expect, when they expect it and how much they are willing to pay for it. Having such knowledge at the outset helps providers in designing more effective offerings.

In addition, participative customers provide updates of their status (Jaakkola \& Hakanen, 2013) and evaluate the alternative paths presented to them during the project (Aarikka-Stenroos \& Jaakkola, 2012). Continual feedback between the parties then enables everyone to know the sequence and timing of the implementation activities (Kellogg \& Nie, 1995). In this way, providers can adjust aspects of the service to customers' preferences and reduce unexpected situations that would affect the outcomes of projects and generate costly mistakes (Fang, Palmatier, \& Evans, 2008). Moreover, customers that actively participate execute the activities they are in charge of on time and help to solve potential complications during the service implementation (Bettencourt et al., 2002), reducing possible delays in the KIBS delivery. Lastly, more effective solutions can be delivered if customers are willing to adapt their processes to accommodate modifications requested by suppliers and in response to unforeseen situations (Tuli et al., 2007). Customer participation, therefore, enables a smoother implementation of the offering (Bettencourt et al., 2002) and reduces the uncertainty inherent in these processes (Stewart et al., 1998), increasing the effectiveness of the KIBS delivered. Furthermore, when customers participate over a period of time, relationships between them and their providers strengthen and so become more resilient and resistant to faults (Eisingerich et al., 2013).

\subsection{Enablers of Customer Participation}


Certain conditions must be in place for customers to participate in the delivery of knowledgeintensive, customized services, such as KIBS. Customers need to be clear about their roles (Bettencourt et al., 2002; Lengnick-Hall, 1996; Mills \& Morris, 1986), know the tasks they have to execute, and know their responsibilities (Dellande et al., 2004). Customer expertise - the knowledge customers have of how the service is to be delivered and of how to assess its performance - is another enabler of customer participation (Auh et al., 2007; Bell, Auh, \& Smalley, 2005). Compared to less knowledgeable buyers, expert customers are more capable of executing service tasks (Eichentopf, Kleinaltenkamp, \& van Stiphout, 2011), of communicating their requirements (Böstrom, 1995) and of making finer distinctions between service attributes (Bell \& Eisingerich, 2007). Customers also have to show motivation to participate (Büttgen et al., 2012; Eisingerich \& Bell, 2006). According to the data of Dellande et al. (2004), customers that actually want to participate benefit most.

Providers can also implement actions during the service delivery to further enable customer participation. Providers can, for instance, educate customers. In teaching customers to execute tasks (Eichentopf et al., 2011), guiding them in their decisions, providing reliable and timely information for their consideration (Auh et al., 2007; Howcroft et al., 2007), and helping them to understand such information (Eisingerich \& Bell, 2008), providers increase customers' expertise (Bell \& Eisingerich, 2007) and participation (Eisingerich \& Bell, 2006). KIBS providers can also try to foster customer participation with the use of socialization practices (Bettencourt et al., 2002; Böstrom, 1995; Büttgen et al., 2012), for example environmental cues, reinforcement methodologies, and peer observation (Kelley et al., 1990). Activities to manage customers' problems, such as accommodating customers' requests and putting effort into solving their problems, could also stimulate their participation because they then feel their concerns are being taken seriously (Eisingerich \& Bell, 2006).

\subsection{The Limits of Customer Participation}


Customer participation, as we have discussed, is important for the delivery of effective KIBS, but many factors prevent customers from being actively involved in the delivery process. For instance, KIBS customers increasingly do not understand what they are buying because non-core internal processes are being outsourced more frequently, leading to the dissipation of technical capabilities in these areas (Flowers, 2007). A lack of role clarity and expertise can also hinder customers' willingness to participate (Larsson \& Bowen, 1989). In addition, customers may not have the resources to maintain an intensive interaction during the project (Töllner et al., 2011) and may display limited motivation to participate in low-priority projects or in projects that only supply additional capacity (Skjølsvik et al., 2007). Furthermore, when KIBS providers are hired by contractors, direct communication with the end customer may suffer (Windahl \& Lakemond, 2006) because the latter may wish to delegate all participation responsibilities to contractors.

To avoid these situations, KIBS firms can attempt to choose the customers they work with. However, not all providers enjoy the economic conditions that allow them to be selective (Skjølsvik et al., 2007) and therefore have to find ways to overcome limited customer participation. These can include informing customers of their responsibilities (Bettencourt et al., 2002; Böstrom, 1995) and investing in customer education and socialization actions. However, if customers do not have resources available, they may be limited in their ability to take part in training programmes, and if they are not motivated to participate upfront (Dellande et al., 2004), they probably will not actively engage in customer education and socialization initiatives either.

In such instances then, how are KIBS providers able to manage service deliveries? Currently, there is a lack of knowledge in this area of research and so, to make a contribution to understanding how KIBS providers can operate effectively in these situations, we conducted a multiple case-study investigation to examine the strategies adopted by KIBS providers and the outcomes of these strategies for KIBS effectiveness. 


\section{Methods}

Case studies enable researchers to obtain a great deal of detail about inter-organizational relationships and to understand causal links in detail (Easton, 2010). They also allow the observation of the phenomenon in its natural setting and the consideration of its contextual aspects (Stake, 1995), enabling a deeper understanding of how business relationships are influenced by contingency factors and irregular occurrences (Ryan, Tähtinen, Vanharanta, \& Mainela, 2012). Hence, the case-based research allowed us to understand further the many aspects of the relationship between KIBS providers and their customers and to uncover new insights in relation to the literature. The specific research design and methods adopted in this study are described next.

\subsection{Case Selection}

The research was conducted in three small UK-based KIBS providers. The case selection was based on two aspects. First, the companies are typical KIBS providers and the level of customer participation varies across service deliveries. Second, providers do not select customers in advance (c.f. Bettencourt et al., 2002; Böstrom, 1995) and, being small, have limited resources to invest in upfront customer training. The implications of the companies' size for the research contributions are explored later. The companies are, therefore, representative cases and provide a good understanding of the phenomenon of interest (Yin, 2003). The cases are also from different

industries and have different types of customers, providing a view of how results vary according to the setting. The cases are described next.

\subsubsection{Softdev}


Softdev Ltd. is a bespoke software developer with 25 years of experience in the market. We researched the General Systems Division, which is responsible for the design and support of bespoke software. The main activities involved in creating bespoke software are: 1) understand the needs of customers, by defining the flow of information to be managed, the information required and the way to distribute and retrieve it; 2) prepare technical specifications of software; 3) code, test and debug software; 4) make software available to customers; and 5) upgrade software and support customers. Customers' specifications tend to describe the functionality expected from the applications instead of providing technical requirements. In addition, Softdev's customers frequently buy software to support the implementation of new processes; for example, the company developed a tool to support the adoption of business continuity in one city council. As such, it can be difficult for them to provide relevant information on the process to be managed. Furthermore, many constituencies at the customers' organization are involved, each of which may treat the service acquisition with a different priority level. Once the service delivery starts, the company adopts a customer-facing software development methodology, which entails frequent interactions with customers to specify and implement offerings.

\subsubsection{Audiosystems}

Audiosystems Ltd. is a small firm that employs eight people and started operating 17 years ago. It sells audiovisual (AV) systems for churches, and for institutions in the education market, such as schools and universities. The company designs and installs customized AV systems composed of a combination of equipment like amplifiers, microphones and projectors. The delivery process involves: 1) visiting the customers to understand their needs and evaluate the building conditions; 2) designing the systems, by defining the content of the system and the location where equipment should be installed; 3) ordering AV equipment; 4) putting the wires in, physically installing equipment and testing the functionality of the system; 5) training customers to use the system; and 6) supporting faulty equipment. Education institutions tend to have formal buying processes and a team of employees with knowledge on AV systems, who are responsible 
for specifying and buying the systems. Churches, in contrast, have informal buying processes and do not provide written specifications. Buyers are often clergypersons and volunteers, who often do not know how AV systems work. In addition, because churches rely heavily on volunteers, the person joining the initial visit might just be someone with access to the building and only a vague idea of what is needed. These issues limit their ability to provide information about the site and about systems' expected functionality. Volunteers are also not the final buyers of the AV system and, thus, are not always interested in assisting Audiosystems' employees. Finally, on the occasions when Audiosystems works for construction companies to implement AV systems as part of larger projects, it has little access to end-users.

\subsubsection{CRControls}

CRControls Ltd. is a small firm that employs seven employees and has operated since 1995 in the same market. Based on customers' specifications and drawings, the company designs and installs building control systems capable of remotely controlling room conditions, such as temperature, pressure and humidity. The delivery process involves: 1) evaluating specifications provided by the customer; 2) defining the equipment to manage the conditions of the room, such as filters, sensors and fans, and their location; 3) programming the piece of software that commands how the system's components should interact and work; 4) preparing specification of the control board; 5) outsourcing the control board production and the system installation; 6) supervising the installation and commissioning the system; 7) training users to operate it, and 8) supporting faulty equipment. There are two main types of customers: end-users, who buy the systems for their own buildings; and intermediary customers, such as clean- and cold-room

providers, who subcontract the control systems to CRControls. In the latter case, CRControls' access to end-users can be quite limited. The specifications from contractors are also a translation of end-users' specifications and may contain requirements that take the interests of contractors into account as much as those of end customers. In many instances, customers also do not know what the best control system would be and rely on the provider to tell them. 


\subsection{Data Collection}

The unit of analysis was the relationship between customers and providers during KIBS delivery processes. We investigated the inputs provided and the activities executed by customers, the actions associated with the interaction between the parties, and the influence of these actions on KIBS effectiveness. We assessed the effectiveness of KIBS from the perspective of providers, based on data available from interviews and documentary sources as to the firms' ability to meet deadlines and keep prices at the contracted levels and their views on the functionality of the solutions offered. The companies did not allow us to contact their customers and, thus, we could not determine the extent to which the solutions provided actually met customers' needs. However, the data collected shows providers' ability to deliver what was agreed between the parties and, thus, also partly indicates how effective the KIBS were to customers.

To collect data, two methods were combined, for the use of different sources can yield a more complete and contextual representation (Jick, 1979). The main method was semi-structured interviews, which was combined with the analysis of documents. In the first interview with the key contacts, we asked questions about the KIBS delivery process stages, the customers served, the practices to stimulate customers' participation and the employees working at the interface with customers. Then, all employees involved in the design, implementation and support of the service in each company were interviewed to obtain information on the KIBS delivery process, on the interaction with customers, on the problems associated with customer participation (or the lack of it), on the strategies used to overcome problems, and on the outcomes of these strategies. Some of employees were interviewed more than once and 16 interviews were carried out. Interviewing all the individuals involved in the process provided a richer understanding of the role of customers throughout the KIBS delivery (cf. Piekkari, Plakoyiannaki, \& Welch, 2010). Table 1 lists the interviewees, the number of interviews conducted with each one, their roles, and the process stage in which they interact with customers. 
Insert Table 1 Here

Semi-structured interviews were adopted because open-ended questions allow rich data to be collected and the research protocol maintains the researcher in its general line of inquiry. Taking advantage of these features, we did not follow the order of the protocol (Appendix A); rather, questions were introduced whenever they made sense to maintain the flow of the interview (Denzin \& Lincoln, 1998). All interviewees were, however, asked questions on the same topics. Participants were also left free to express their views and raise new issues to collect data on contextual and unexpected issues (cf. Ryan et al., 2012). The interviews lasted between one and three hours and contained extensive descriptions of the KIBS delivery processes and of the role played by customers in them. All interviews were made in person and recorded. Based on the transcription, a short summary was prepared and sent to the interviewees, who checked the content and made suggestions to clarify certain issues.

In addition, documents and emails were analysed to understand further the inputs provided by customers. We reviewed specifications with different levels of detail, quotation forms sent to customers with the service proposals, emails exchanged between customers and providers, and forms and templates used to share information with customers. The providers' websites were also analysed to obtain more information on the KIBS offered. Documents mainly provided information on the variability of customers' inputs, on the interaction between the parties, and on project performance, such as costs and delivery dates.

\subsection{Data Analysis}

Data were analysed close to their collection date. Questions that emerged during the analysis were asked in a follow-up interview or by email. NVivo 9 Software was used to support the 
IMM 13-140

analyses because it facilitates the coding process and the categorization of codes. Cases were first analysed individually. Following the coding guidelines of Miles and Huberman (1994), this process started with four theoretical categories: enablers of customer participation (CP), examples of $\mathrm{CP}$, actions to manage $\mathrm{CP}$, outcomes of $\mathrm{CP}$. Data were then carefully read and pieces of text were classified into these categories. In several analysis rounds, codes were reclassified into new categories that emerged during the process. The final set of categories is in Table 2.

Insert Table 2 Here

In order to answer our research questions, we separated units of analysis into two groups. One contained KIBS deliveries with lower levels of customer participation and the other deliveries with higher levels of customer participation. Tables were then created to compare the categories identified across the groups. The outcomes of the analyses were used to prepare reports for the companies with the research results and follow-up interviews with the key contact in each company were conducted to validate the findings. After this validation, the cross-case analysis was carried out. Finally, the data analysis outcomes were associated with the research questions and theory was used to make sense of them.

\section{Outcomes of the Data Analyses}

In this section, we present the strategies providers adopt to manage KIBS deliveries to less expert customers with different levels of motivation to participate. We also discuss the relationship between these actions and how they create benefits for customers.

\subsection{Strategies to Manage Variation in Customer Participation}


We identified that providers adopt three types of strategies to manage KIBS delivery processes characterized by limited customer participation. They are: customer education, preventive actions, and problem management actions. It is worth mentioning that we found no examples of customer socialization actions that aimed at sharing norms, values and cultural perspectives with customers. This may have been due to the size of the companies researched. The data also suggest that the customers of Audiosystems and CRControls are generally less participative than the customers of Softdev (Table 3).

Insert Table 3 Here

\subsubsection{Customer Education}

In line with the literature, the interviews suggest that, to prepare a technical specification both parties agree with, providers educate customers. Providers use their technical knowledge and experience to ask questions and explain to customers how systems work, increasing customers' expertise. In the case of Audiosystems, this is done mainly in the initial visit to the churches. The System Designer explained that they ask many questions to identify the functionality expected from the AV systems, such as: will you be you using this system for music and speech? Will you want to plug a computer in or will you want to play DVD's or use any cameras? Will everybody see the central screen or will you have people in other rooms that might want to see a relay screen? They also try to reduce the knowledge asymmetry between the parties.

"We often have to ask them so many questions: 'Have you thought about this? Would you do it like that? What about this?' Often within that, with a lot of customers, particularly church sector because we work with amateur people, they often don't understand things. So often I find myself giving a basic explanation of the technology to them, to help them kind of understand it. So in order for them to give a satisfactory answer to something I've asked them, I often have to give a basic explanation of the technology." (Audiosystems, System Designer) 
At Softdev, besides this interaction to assess customers' needs, software developers create templates to show customers basic aspects of the application. We were able to review examples of printed screens shown to customers at the beginning of one project. They demonstrated the login page, some drop-down menus, and which sort of data would be in the screens. In addition, Softdev develops applications to support new organizational practices in customers' organizations and, as such, the company sometimes invites third-party consultants with knowledge of the methodology to support projects. This was the case for the development of a business continuity tool.

"We produced a far more detailed spec from that, which included screenshots... I'm not sure how many iterations we went through that, but I would say that there would be five or six versions of that release... There was a point during which we were having weekly conference calls with them [the customer]... And that is literally before you start any coding, this is only getting the specification. And the other person we got heavily involved in that was [names consultant]. Because he knew a lot about business continuity, which is the purpose of the tool, and we didn't, we also used him and we had weekly meetings with him for about two or three months." (Softdev, Project Manager)

The questions, the support from consultants and the use of visual resources help customers to understand better what they are buying, and providers to learn more about customers' needs. This reduction in the knowledge asymmetry between the parties then increases the quality of the resources provided by customers and facilitates the creation of detailed specifications. During the interaction with customers, the companies also have the opportunity to instruct customers on the inputs they need to share and on the activities they need to perform, increasing customers' role clarity. Interestingly, the analysis of documents collected showed that the companies do not add the responsibilities of customers to service specifications and contracts signed between the parties.

Softdev is the company studied that makes more extensive use of customer education actions. The company uses the customer-facing software methodology in all its service deliveries, even though some customers get more actively involved in the service delivery than others. The 
company also employs actions to educate customers during the coding stage, but it does so with less intensity than during the solution design stage. The Project Manager mentioned that they are careful with the number of prototypes they show customers because this can increase the modifications they want to make to the applications. Customer education, however, requires customer-provider interaction and the customers of CRControls, in general, are less motivated to take part in meetings.

“Unfortunately, although people don't like to admit it, jobs are run exclusively on cost rather than the quality of the work you will get at the end of the day. So, we have to price competitively and generally that doesn't include meetings. Basically we have to try to do things as lean as possible.” (CRControls, Project Manager)

CRControls relies little on customer education actions. Systems are designed mainly based on the specifications provided and the Design Engineer uses emails or phone calls to clarify aspects of the specification. Only occasionally does the company have a pre-contracting meeting with its customers. During the service delivery, parties interact by email to exchange information on deadlines and installation dates. Then, during the commissioning stage, the Project Manager teaches customers the functionalities of the control system and simple troubleshooting procedures. Audiosystems is in between Softdev and CRControls when it comes to the use of these actions, for this kind of interaction with customers happens mainly at the beginning of KIBS delivery processes during the site visits.

\subsubsection{Preventive Actions}

KIBS providers also rely on less interactive measures to compensate for customers' lack of participation and engagement in customer education activities. CRControls and Audiosystems rely more heavily on this type of strategy. The data showed that the experience acquired in previous jobs enables providers to keep working, despite customers' inability to provide information. For instance, because churches may take several months to approve the installation of the system, the System Designer takes many photos, during the initial site visit, of particular 
aspects of the building he knows are relevant to designing an AV system. In this way, he does not need to do another site visit if customers ask for alterations six months after the initial site visit. In addition, when the company is working with customers they already know, they do not do the initial site survey and only talk to customers over the phone.

At CRControls, one of the interviewees mentioned that the Design Engineer knows whom to contact to obtain technical information about how other systems and devices being installed in the building (e.g., fire alarms and access control systems) communicate with control systems, if customers are not able to supply the information. In an informal discussion, the Design Engineer explained that this is particularly useful in larger projects because in these projects he needs to obtain information on how many devices communicate with the control systems. In addition, he relies on his knowledge of customers' needs and of the technology to fill in gaps left by incomplete specifications.

"You have to understand what is important to that customer. So, for example, when you go to the clean rooms, you don't really worry about leak detection, because leak detection is not that big of a deal for clean rooms. But leak detection is very important in data centres. You have to know that. So when you do get a customer that comes along and has a data centre, you have got to know you've got to put leak detection in because he won't necessarily ask you. But then when you finish, he will ask you: 'You did put a leak detector, didn't you?", (CRControls, Owner and Design Engineer)

A quote from the System Designer of Audiosystems also revealed that experts' knowledge and experience enables them to identify upfront how uncertain jobs might be and to make assumptions about how customers might change their minds. As such, they can prepare for it.

"Sometimes I'll second-guess them and we are doing a job and I'll add bits to the systems at my expense in the anticipation that they might ask for that later. Sometimes it pays, sometimes it doesn't. Sometimes you end up with cables that will never be used, but most of the time they will come back and say 'Oh... we should have had that control panel' and you know you already have put the wiring in and you have a winner...[Long paragraph to explain that sometimes he adds extra cost allowances on his account]...I only use contingency margins if I know I'm going to need them. If there is very little that can go wrong and I wouldn't put a contingency in there. On the jobs that are less certain I would...Sometimes I'd just mark it on the quote 'plus contingency of 250 pounds'. We only use it if we really need it." (Audiosystems, Owner and System Designer) 
The Design Engineer of CRControls confirmed that they also second-guess customers frequently. However, according to the Project Manager, the company does not use contingencies because this is not a common practice in the industry. Softdev makes little use of preventive actions; most of the relevant information is obtained from customers.

\subsubsection{Problem Management}

KIBS providers also adopt problem management actions to control unexpected situations that result from limited customer participation. All the three companies acknowledged that customers can realize that the software or systems being developed have features they did not expect or do not have features they did expect. This is mainly due to discrepancies between what customers really wanted and what providers understood they wanted. The KIBS providers mentioned that when they know they have estimated something wrongly at the quotation stage, e.g., they estimated two suction valves for the control system and then used four, or they have assumed it wouldn't be necessary to pass cable from one point to another, they tend not to charge customers extra. Costless and minor changes are also made without charging customers for them. In addition, providers sometimes do not charge customers even for more significant alterations in the systems. The data also revealed that providers use their knowledge to explain why the alternative implemented is better or to come up with new ideas, which will not require much effort to accomplish.

"You will always have times where [mentions the System Designer's name] idea and the customer's idea are slightly different and when we actually come to do the installation, they are like 'that wasn't what I was thinking'. But when you explain the situation, they say: 'Yeah, I understand why you have done that."' (Audiosystems, Installation Manager)

Audiosystems also keeps customers informed of eventual changes in specifications that customers are not expecting. For example, in the case of the churches, because of their long buying process, by the time the systems are finally approved for installation, the equipment 
suggested in the proposal is outdated and needs to be replaced. In such cases, the Installation Manager always approaches the customer before starting the installation to explain the differences in the equipment being installed. The Project Manager of Softdev also made a similar point.

"The other thing for bespoke development is that the most important thing is to keep the customer informed. Quite a lot of suppliers think 'things are going wrong but I'm not going to talk to the customer' and you've got to talk to the customer, because the more you let problems build up... because you usually find that if you keep a good relationship with the client and talk honestly to them, they might not be happy, but they might just say, 'Ok, that is fine."' (Softdev, Project Manager)

Customers can also change their preferences during the implementation of the KIBS. In such cases, providers appear mainly to use their knowledge and experience to evaluate if the change requested is viable and good. The three companies, when facing such situations, evaluate the new requests of customers. If the option is not good, the companies tend to do as explained by the Software Developer of Softdev:

"Because the customer is paying for something they want just for them, you do it the way they want. We advise them if it's not going to work, but..." (Softdev, Software Developer)

Additionally, in these cases, providers also tend not to charge customers if the costs associated with changes are not significant. However, if the costs are significant, they explain to the customers that they will have to pay for it to avoid any surprises and disagreement between the parties when the invoice is sent to the customer. Providers also often need to use their problemsolving skills to provide fast quotes for changes in systems designs. This is common at CRControls because many alterations are requested on site during the installation of the control systems.

'If it is a no-cost change to us, we do tend to say, 'Don't worry about it, we'll just do it.' If there is a cost, then we have to...hopefully before we do it...say: 'This is the cost that comes with the addition of that.' But it often happens that you are on site and they ask you to change it. That is when you always have difficulties...Y You do have to make it absolutely clear at that time that if I change it now, it's going to cost and, the least you have to do is to give them a partial figure. You can at least say, 'It's going to take half a day and cost you 200 pounds.' You've got to do that. If he nods then you can carry on, if not, you don't carry on." (CRControls, Owner and Design Engineer) 
All three companies rely on problem-management measures during the implementation of KIBS. Each company was more emphatic about certain measures though. For instance, CRControls and Softdev both are willing to incur more significant costs to maintain the quality of their offerings and find it very important to be clear with customers about additional costs they might be liable to, if they change their minds. Audiosytems and Softdev also emphasized that maintaining a good and open communication with the customer in case of unexpected situations is fundamental. In the case of CRControls, providing fast quotes for design alterations is common, for the firm normally works with third parties on site and has to decide together with them what ought to be done. All companies, however, agree that they commonly acknowledge mistakes, make small alterations for free and orient customers if their design changes are unwise.

\subsection{The Outcomes of Providers'Strategies}

The three companies reported that the low quality of customers' specifications and information and the lack of customers' compliance with providers' instructions cause changes in the specification of systems and in the installation conditions during the implementation stage. These changes then can cause conflicts between the parties, lead to delays in the service delivery and increase the chances that customers will be delivered KIBS that do not meet their expectations and needs. The Design Engineer of CRControls explained how incomplete specifications create such situations.

"It's difficult when he says... because you were given a vague spec in first place... when he says: 'Well, that is not what we have anticipated. We don't like that. That's not what we want. You need to change it. You change it now.' And you say: 'You didn't tell us. That is what we thought it was, right?' He can come back and say, 'Have you asked?' It can get a bit messy if you are not careful." (CRControls, Owner and Design Engineer)

However, providers' actions can increase the likelihood that they are able to offer more effective solutions. The data suggest that customer education actions are particularly useful for this 
purpose. The Project Manager of Softdev pointed out that guiding customers and interacting extensively with them during the technical specification preparation stage is fundamental to pinning customers down and capturing their needs. Providers are then able to design solutions that are better aligned to customers' requirements, reducing the number of problems faced during the service delivery, as related below. The designers of CRControls and Audiosystems provided similar statements.

"But what you've got is a specification that is agreed. So you've got your database design sorted and your specification. And if you don't spend your time in that and you start coding, it will obviously create more problems as you go along. Because you find that you are deep into coding and you suddenly realize that something is not going to work or the client says something and then you've got to go back and potentially do a lot of rework." (Project Manager, Softdev)

Preventive actions also contribute to effective delivery of KIBS. According to the Design Engineer of CRControls, in many cases, customers do not specify certain aspects of the system and expect them to be there anyway. For instance, as mentioned previously, leak detectors are very important in control systems designed for clean-rooms. As such, leak detectors are always added to the systems designed for these sites, even when they are not listed in customers' specifications. In this way, despite the lack of information, providers are able to deliver the functionality that is important for customers. Furthermore, the System Designer at Audiosystems explained that sometimes the use of assumptions and contingencies does not pay off for the company because customers do not request the alterations anticipated. However, when customers do change their minds, costs are saved and delays are avoided.

Preventive actions can also reduce the amount of resources customers need to employ in the KIBS delivery. For instance, customers of CRControls do not have to search for technical information on other equipment being installed in the building. The customers of Audiosystems also save resources when they do not have to join providers during site visits, as described below:

"Because I've done so much there, if the IT man rings up and says to [the System Designer] 'I need a classroom doing', [the System Designer] doesn't really go to see it 
IMM 13-140

unless the customer says 'I think you really need to come and see this."' (Audiosystems, Installation Manager)

The data however suggest that customer education is better than preventive actions to increase KIBS effectiveness. The Project Manager of CRControls mentioned that, even though most of their communication with customers happens via telephone or email, face-to-face interaction is better to guarantee a smoother implementation of systems.

Problem-management actions are then good to fine-tune KIBS offerings to customers' needs. This is the case when, for instance, the Installation Manager of Audiosystems makes small alterations during the installation to bring the system closer to customers' desires and advises customers against unwise changes. Such actions also help reduce delays because customers get new options that satisfy them during the installation of systems. Furthermore, not charging customers for certain alterations in KIBS designs maintains the price of KIBS at the agreed level. Although such alterations have costs for KIBS providers, the companies seem to believe the associated benefits outweigh these costs. Softdev's Project Manager, for instance, mentioned that sometimes it is better to trade costs for quality and reputation. The Service Manager of CRControls also explained that they do this to increase the chances of customers' buying new control systems in the future and of hiring support services.

\section{Discussion}

Based on the data analysis outcomes and on insights from the literature, we propose a framework (Figure 1) to represent how providers overcome limited customer participation and are able to provide effective KIBS to their customers.

Insert Figure 1 Here 
The framework should be interpreted in the following ways. First, customer participation should have a direct positive effect on KIBS delivery effectiveness. As proposed in the literature, customer participation leads to the delivery of more effective KIBS because solutions are designed based on more reliable information and constantly adjusted to customers' needs during the delivery process. Second, under lower levels of customer participation, providers adopt at least three strategies to overcome the challenges posed by limited customer participation. The three strategies adopted are problem-management, preventive and customer education actions. These strategies are used in a complementary way during the service delivery, an association represented by the arrows connecting the strategies in the framework. Third, providers' expertise gives them the ability to execute these three types of strategies and is, thus, a key enabler of providers' strategies. Fourth, customer education actions help customers provide better inputs to the KIBS delivery process and, therefore, may lead to more customer participation. Fifth, preventive and problem management actions contribute to a better KIBS effectiveness. These two strategies enable, respectively, providers to obtain inputs that customers do not provide to design solutions and refine aspects of the solutions delivered, contributing to the on-time delivery of the KIBS agreed between the parties without or with little additional costs. The relationships represented in the framework, their practical and theoretical implications are discussed in the following subsections.

\subsection{Overcoming Limited Customer Participation}

In line with the current literature, this study shows that providers engage in customer education actions to improve customer participation. When providers explain to customers basic aspects of the technology, ask questions and show how solutions will work, customers can understand better what they are buying and what they should do. Customer education helps to increase customers' expertise and role clarity (Bell \& Eisingerich, 2007; Eisingerich \& Bell, 2006) and, thus, makes them more capable of sharing relevant information and supporting decision-making (Yim et al., 2012). 
In addition, this study shows that providers rely on preventive and problem-management actions to deal with the lack or low quality of customers' inputs. Preventive actions reduce providers' dependence on information coming from customers and on the activities they execute. This is the case when CRControls, Softdev and Audiosystems, respectively, contact other sources to obtain technical specifications of the control systems, add contingencies to projects, and use experience to complement customers' specifications. If compared to customer education actions, which help to increase customer participation, expertise and role clarity, preventive measures circumvent limited customer participation. Problem-management actions are then employed to alleviate the impacts of specification changes, resulting from limited customer participation and from process variation due to customers' new demands. As a result, the functionality of the services delivered is improved and additional costs and delays are avoided. This is the case, for example, when the companies compensate customers for the problems resulting from incorrect specifications by making alterations in the KIBS design for free. CRControls also reduces possible delays in the service delivery by providing quick quotes for changes resulting from incorrect specifications or specification changes.

Therefore, albeit in different ways, customer education, preventive actions and problemmanagement actions are used to overcome the challenges posed by limited customer participation. When customers participate more, providers can then rely less extensively on the strategies. For instance, the System Designer and owner of Audiosystems explained that he does not use contingencies and add extra cost allowances when jobs are less uncertain and he knows that very little can go wrong. The Project Manager of Audiosystems also mentioned that efforts to educate customers are usually more necessary with churches than with education institutions because customers of the former sector have little knowledge of what they are buying.

Providers also seem to make use of these strategies with different intensities depending on the extent to which customers have the resources and upfront motivation to interact with KIBS 
providers during the service delivery. The Project Manager of CRControls clearly stated that due to the structure of the industry they operate in, their customers hardly ever allow time for meetings and interpersonal interaction. Technical specifications and customers' demands are mainly aligned by email or on the phone. At Audiosystems, the designers of the systems also use mainly the initial site visit to instruct customers about the features of systems, help them choose equipment and align expectations. As such, in many circumstances, the employees of these two companies use their knowledge and experience to build assumptions, do their work differently and obtain relevant information from other sources. Conversely, when customers interact more with providers, they use preventive measures to a lesser degree. At Softdev, the customer-facing software development methodology creates means for the company to guide customers throughout the service delivery, so the company makes little use of contingencies and assumptions and obtains customer-related information mainly from customers. Softdev also use fewer problem-management actions than the other two companies.

The outcomes described in this section have theoretical and practical implications. First, in addition to customer education and problem-management strategies (Eisingerich \& Bell, 2006), providers employ preventive actions during the KIBS delivery and use the three actions in a complementary way during each service delivery. As such, research not considering the role of preventive actions and looking at only one (Bell \& Eisingerich, 2007; Evans, Stan, \& Murray, 2008) or two (Eisingerich \& Bell, 2006) of these strategies can provide only a partial representation of how providers manage customer participation in KIBS. In addition, while customer education may increase customer participation, preventive and problem-management actions compensate for the lack of it. This could explain why previous research did not find a significant association between problem management and customer participation (Eisingerich \& Bell, 2006). The role of each type of strategy and their association with customer participation should thus be considered in future research.

Furthermore, although lower levels of customer expertise and role clarity probably require more customer education (Eisingerich \& Bell, 2006), lower customer motivation seems to lead to the 
use of more preventive actions because customers do not want to interact with providers and engage in customer education actions. Researchers should, therefore, consider the combined influence of the different levels of customer expertise, role clarity and motivation to study customer participation in KIBS. From a more practical point of view, this study suggests that KIBS managers should use the level of customers' willingness and ability to participate as segmentation criteria and, based on this, define the combination of strategies most effective to serve each type of customer.

\subsection{Providers' Strategies for Improved KIBS Outcomes}

Existing research suggests that customer participation in the context of knowledge intensive offerings can improve the service delivery effectiveness (Kelley et al., 1990) and positively influence customer satisfaction (Yim et al., 2012), customer loyalty (Auh et al., 2007) and the value customers see in purchasing the service (Lapierre, 1997). The present study adds to our knowledge of these relationships by showing that customer education, preventive actions and problem-management actions also contribute to the delivery of more effective KIBS in two ways.

First, customer education has the potential to increase customer participation and this, then, contributes to increases in the effectiveness of the KIBS provided. For instance, the Softdev case shows that guiding customers and using consultants while preparing the technical specification

helps in capturing the actual needs of customers. Hiring consultants also increases the knowledge of Softdev's software designers, who then become more qualified to help customers specify their needs. Through customer education, providers learn more about their customers and can then prepare better service specifications, rule out alternatives that would not be interesting to customers and make more informed decisions. Ultimately, providers are able to design better solutions and minimize problems resulting from low quality specifications that could cause 
IMM 13-140

delays and extra costs. Customer education actions seem, therefore, to have an indirect positive effect on KIBS effectiveness.

In addition, preventive and problem-management actions can improve KIBS' effectiveness. For instance, the use of contingencies enables CRControls and Audiosystems to accommodate possible design changes without customers noticing that a mistake was made in the first place. In addition, when providers can avoid additional meetings and site visits because they can obtain information elsewhere, the costs of the project are reduced or maintained at the agreed levels. Furthermore, in making small alterations during the installation of systems, the Installation Manager of Audiosystems fine-tunes the systems to customers' demands and, if customers are pleased with these small alterations, delays and additional costs are avoided. Providers are also able to maintain jobs at the estimated price by not charging customers for changes in systems' designs.

Preventive and problem-management actions, therefore, complement lower levels of customer participation when needed and help solve the problems arising from it. The quote below shows how customer participation enables a smoother implementation of the offering, leading to a certain level of KIBS effectiveness. However, delays can still happen and problem-management actions can then be employed to minimize delays and additional costs.

"A client basically told us, 'The job is yours, put a sensible price on it, we won't look anywhere else.' In those instances, we have allowed for a half-day meeting once a week. The job goes like clockwork then, because everyone knows what is going on. Everyone keeps you updated on their progress and, obviously, it there are any delays, you know about it pretty much straight away." (CRControls, Project Manager)

In summary, in spite of the heterogeneity in customers' willingness and ability to participate, providers' strategies enable the delivery of effective KIBS. The effectiveness of KIBS, therefore, depends as much on providers' efforts to manage customer participation as it does on customer participation as such. Future studies on customer participation should not only see providers' 
strategies as a way to increase participation, as research has so far considered (Büttgen et al., 2012; Eisingerich \& Bell, 2006), but also as actions that improve the outcomes of it.

There is also an important practical implication associated with this research outcome. The cases showed that face-to-face interaction and customer education actions are better than preventive actions in guaranteeing a smoother implementation of systems. It could then be argued that customers with fewer resources and lower motivation to take part in meetings and engage in customer education actions tend to receive less effective KIBS. As customers value sacrifices and benefits differently (Ulaga, 2001), some of these customers may not mind. Others, however, may not be satisfied with the service provided. KIBS providers, in order to avoid such situations, could offer alternatives to customers, who would be able to choose, for example, if they prefer to get more involved and increase the effectiveness of the KIBS purchased or just keep their involvement in the delivery process as low as possible. Alternatively, providers could offer customer education actions as an optional service. This would be particularly interesting for more cost-oriented industries, like the ones of Audiosystems and CRControls, in which most customers may prefer to get as little involved as possible in KIBS deliveries, but some might actually choose to get more involved to get better offerings.

\subsection{The Role of Providers' Expertise}

In addition to inspiring customers to comply with providers' rules and instructions (c.f. Dellande et al., 2004; Lin \& Hsieh, 2011) and to being a key resource of the KIBS productive process, the expertise of KIBS employees gives firms the ability to put customer education, preventive and problem-management strategies into practice. For example, to guide customers, provide alternatives and second-guess customers, the System Designers of Audiosystems rely on their experience of what other customers frequently buy, of the equipment customers tend to choose, and of what normally works well. They also use their knowledge of the technology to give explanations to customers and ask questions, such as: Have you thought about this? Would you 
do it like that? What about this? Providers' knowledge of what customers tend to buy, of markets, and of technologies also enable them to create assumptions and estimate the necessary contingencies. Additionally, the Project Manager of Softdev explained that in many cases they have to use their expertise to convince customers that their demands are not reasonable and offer alternatives. At Audiosystems, the Installation Manager pointed out that he simply knows that some customers are not satisfied and, in these cases, he approaches customers to offer alternatives that might save the situation. The Design Engineer of CRControls also relies on his ability to solve problems quickly, together with his knowledge of prices and costs, to offer lastminute quotes.

The present study thus raises awareness of the importance of managing this key productive resource for KIBS firms, by showing how providers' expertise is deployed during the entire delivery processes to support the interaction with customers. Researchers should consider the possible ways in which providers' expertise, or lack of it, might influence future studies on customer participation. KIBS providers, in their turn, should consider customers' willingness and ability to participate to define the expertise levels needed to deliver the service. When providers have limited expertise, for example, when KIBS providers are entering a new market (see Santos \& Spring, 2013) or when manufacturers move into the provision of integrated solutions (see Windahl \& Lakemond, 2006), they should serve mainly expert and motivated customers until they are capable of competently making use of customer education, preventive and problemmanagement actions. Providers should also try to match employees' expertise to the types of actions most used in serving each customer. For example, for less motivated customers, providers should allocate teams composed of individuals with a greater ability to deal with uncertainty and with experience in working with similar customers. For customers that are willing to engage in customer education actions, providers should allocate teams with more relational selling abilities in order to increase the trust and commitment between the parties and, thus, the quality of the relationship (c.f. Athanasopoulou, 2009).

\subsection{Implications of the Context of Analysis}


The context in which we studied customers' participation in KIBS may have influenced some of the research outcomes. The KIBS offerings analysed cannot be considered highly complicated because they do not involve the management and integration of several technologies and multiple companies in the network. Hence, providers have to concern themselves with a smaller set of issues and may be able to depend more on preventive measures and use assumptions, contingencies, and estimates. A comparison between the cases supports this point. Audiosystems' offerings are based on a simpler technology and the company depends on a smaller network of companies to deliver them. Compared to the other two companies, Audiosystems displayed more intensive use of preventive measures. It would, therefore, be interesting to understand further if and how providers' measures to deal with the lack of customer participation change when more complicated offerings are being developed. Additionally, SMEs rely less on established processes, tool-kits and best practices. Employees, therefore, do not have to follow strict rules and procedures and have the freedom to decide how to act in each situation. This may have contributed to the identification of the prominent role of providers' expertise. The lack of use of socialization measures may also be due to the less formal structure of these companies. Finally, we studied the relationships between UK-based firms and their customers. Managers in different countries have alternative views of how to deal with their customers (Kanter, 1991) and may perceive the gains associated with customer management in distinct ways, as shown by Chow et al., (2008). As such, some of the actions to educate customers and manage their problems during the KIBS delivery could be specific to the relationships established between buyers and providers in this country. It would, therefore, be valuable to explore the issues raised in this research in larger KIBS firms in different countries with more established methods and systems.

\section{Conclusion}


In this study, we investigated the participation of customers in KIBS processes to understand how providers overcame the challenges posed by customers' limited willingness and ability to contribute to the delivery process. The case studies, conducted in three small KIBS providers, enabled us to comprehend in depth the different ways customers participate in KIBS, how providers react during the delivery process and the consequences of providers' actions to KIBS effectiveness. Our data analyses led us to propose a framework that captures the relationships between customer participation, KIBS effectiveness, providers' expertise and their strategies to manage the interaction with customers. Ultimately, this framework and the discussions building on it suggest that providers' expertise and the strategies their knowledge and experience enable are as important as customer participation to the successful delivery of KIBS. They enable KIBS firms to overcome the situations caused by variation in customers' profiles and still deliver effective solutions.

The research outcomes thus provide a more comprehensive understanding of how providers handle customer participation in KIBS delivery processes, complementing the existing literature that focuses mainly on the causes and consequences of customer participation. The important role of providers' strategies needs to be considered in the future. The research results also have important implications for KIBS providers. Managers should segment customers based on their preferences and manage customers accordingly. As employees' expertise is the basis of the three types of strategies, KIBS managers should also allocate individuals to projects based on their ability to execute customer education, preventive and problem-management strategies. They should also, while their expertise levels are low, work for expert customers that are willing to participate.

This research has limitations. As explored in the discussion, the companies' size and location may have influenced some of the research outcomes. Furthermore, we looked at KIBS effectiveness from the perspective of providers and, thus, our research results do not show the extent to which the solutions provided actually meet customers' expectations. Finally, the framework does not represent relationships and concepts that have not emerged in the cases 
studied (e.g., customer socialization). Therefore, the research outcomes offer a partial representation of our phenomenon of interest. The aim of this study was, however, to build theory. We used the cases and theory to have a better understanding of how providers manage the lack of customer participation during delivery processes. We also considered the context of our research outcomes to explore their applications and limitations. This process of naturalistic generalization (Creswell, 1997) led to the formulation of a framework that complements the existing literature and should be evaluated and complemented in future research.

\subsection{Suggestions for Future Research}

The research outcomes open new avenues for future research on customer participation in KIBS. There is the need to understand the extent to which our findings can be extrapolated to different contexts of analysis. Researchers also need to look at the issue of customer participation and its outcomes in a more systemic way. To do so, the relationship between providers' actions and customer participation should be studied considering the different levels of customer expertise, role clarity and motivation. The role of customer socialization actions should also be further explored in future research. Furthermore, our data suggest that providers' actions have a direct effect on KIBS effectiveness, but it could be argued that these strategies make customer participation less critical to achieve KIBS effectiveness. Future studies could explore this aspect in more detail. We also need a better understanding of the impact of providers' actions on the benefits delivered to customers, such as service quality, customer satisfaction and loyalty and the value customers see in purchasing KIBS. It would also be interesting to conduct longitudinal research in order to explore more explicitly and systematically the effect over an extended period of time and multiple projects of customers learning to be good customers of a particular supplier. Such research could show how the relationships identified in this paper evolve as customers and providers engage in repeated business relationships. 
In addition, more effort could be employed in extending the scope and depth of the research on customer participation. For instance, it should be explored how the relationship between KIBS providers and their customers are influenced by other companies in the network. Power and workload imbalances in these relationships should, and probably do, affect the ways in which customers dedicate themselves to KIBS deliveries and providers manage their delivery processes. Furthermore, given that "solutions selling" is based on firms' reputation and on the goodwill between the parties, we should try to understand further how and under what conditions providers' actions and customer participation contribute to the establishment of long-term relationships. Finally, more knowledge of the value creation processes of KIBS customers could be obtained from studies on the importance customers attribute to benefits and sacrifices associated with customer participation and providers' strategies.

\section{Acknowledgments}

We gratefully acknowledge funding support from Lancaster University Management School (LUMS) and the practical assistance of Helen Fogg of LUMS in negotiating access to the case study firms. We are grateful for the collaboration of participating firms. We also acknowledge the reviewers and our collegues Dr. Katy Mason, Dr. Anto Daryanto and Dr. José Mauro da Costa Hernandez for helpful comments on earlier versions of this paper. All remaining errors are our responsibility. Martin Spring gratefully acknowledges financial support in the form of an AIM Research Fellowship in Services, ESRC Grant number RES-331-27-0036, and a period of sabbatical leave provided by Lancaster University Management School. The organizations that provided financial support had no involvement in the execution of this study. 
IMM 13-140

\section{References:}

Aarikka-Stenroos, L., \& Jaakkola, E. (2012). Value co-creation in knowledge intensive business services: A dyadic perspective on the joint problem solving process. Industrial Marketing Management, 41, 15-26.

Amara, N., Landry, R., \& Doloreux, D. (2009). Patterns of innovation in knowledge-intensive business services. The Service Industries Journal, 29(4), 407-430.

Athanasopoulou, P. (2009). Relationship quality: a critical literature review and research agenda. European Journal of marketing, 43(5/6), 583-610.

Auh, S., Bell, S. J., McLeod, C. S., \& Shih, E. (2007). Co-production and customer loyalty in financial services. Journal of Retailing, 83(3), 359-370.

Bell, S. J., Auh, S., \& Smalley, K. (2005). Customer relationship dynamics: service quality and customer loyalty in the context of varying levels of customer expertise and switching costs. Journal of the Academy of Marketing Science, 33(2), 169-183.

Bell, S. J., \& Eisingerich, A. B. (2007). The paradox of customer education: customer expertise and loyalty in the financial services industry. European Journal of Marketing, 41(5/6), 66-486.

Bettencourt, L. A. (1997). Customer voluntary performance: customers as partners in service delivery. Journal of Retailing, 73(3), 383-406.

Bettencourt, L. A., Ostrom, A. L., Brown, S. W., \& Roundtree, R. I. (2002). Client co-production in knowledge-intensive business services. California Management Review, 44(4), 28.

Böstrom, G. (1995). Successful cooperation in professional services: what characteristics should the customer have? Industrial Marketing Management, 24, 151-165.

Büttgen, M., Schumann, J. H., \& Ates, Z. (2012). Service locus of control and customer coproduction: the role of prior service experience and organizational socialization. Journal of Service Research, 15(2), 166-181.

Chow, W. S., Madu, C. N., Kuei, C. H., Lu, M. H., Lin, C., \& Tseng, H. (2008). Supply chain management in the US and Taiwan: an empirical study. Omega, 36(5), 665-679.

Creswell, J. W. (1997). Qualitative inquiry and research design: choosing among five traditions. London: Sage Publications.

Dane, E. (2010). Reconsidering the trade-off between expertise and flexibility: a cognitive entrenchment perspective. Academy of Management Review, 35(4), 579-603.

Davenport, T. H., Jarvenpaa, S. L., \& Beers, M. C. (1996). Improving knowledge work processes. Sloan Management Review, 37(4), 52-65. 
Dellande, S., Gilly, M. C., \& Graham, J. L. (2004). Gaining compliance and losing weight: the role of the service provider in health care services. Journal of Marketing, 68, 78-91.

Denzin, N. K., \& Lincoln, Y. S. (1998). Collecting and interpreting qualitative materials. London: Sage publications, Inc.

Easton, G. (2010). Critical realism in case study research. Industrial Marketing Management, 39, $118-128$.

Eichentopf, T., Kleinaltenkamp, M., \& van Stiphout, J. (2011). Modelling customer process activities in interactive value creation. Journal of Service Management, 22(5), 650-663.

Eisingerich, A. B., Auh, S., \& Merlo, O. (2013). Acta Non Verba? The role of customer participation and word of mouth in the relationship between service firms' customer satisfaction and sales performance. Journal of Service Research, 17(1), 40-53.

Eisingerich, A. B., \& Bell, S. J. (2006). Relationship marketing in the financial services industry: the importance of customer education, participation and problem management for loyalty. Journal of Financial Services Marketing, 10(4), 86-97.

Eisingerich, A. B., \& Bell, S. J. (2008). Customer education increases trust. Sloan Management Review, 50(1), 9-11.

Etgar, M. (2008). A descriptive model of the consumer co-production process. Journal of the Academy of Marketing Science, 36, 97-108.

Evans, K. R., Stan, S., \& Murray, L. (2008). The customer socialization paradox: the mixed effects of communicating customer role expectations. Journal of Services Marketing, 22(3), 213223.

Fang, E., Palmatier, R. W., \& Evans, K. R. (2008). Influence of customer participation on creating and sharing of new product value. Journal of the Academy of Marketing Science, 23(4), 322-336.

Flowers, S. (2007). Organizational capabilities and technology acquisition: why firms know less than they buy. Industrial and Corporate Change, 16(3), 15-23.

Grönroos, C., \& Ravald, A. (2011). Service as business logic: implications for value creation and marketing. Journal of Service Management, 22(1), 5-22.

Howcroft, B., Hamilton, R., \& Hewer, P. (2007). Customer involvement and interaction in retail banking: an examination of risk and confidence in the purchase of financial products. Journal of Services Marketing, 21(7), 481-491.

Jaakkola, E., \& Hakanen, T. (2013). Value co-creation in solution networks. Industrial Marketing Management, 42(1), 47-58.

Jick, T. D. (1979). Mixing qualitative and quantitative methods: triangulation in action. Administrative Science Quarterly, 24(Dec), 602-611. 
Kanter, R. M. (1991). Transcending business boundaries: 12,000 world managers view change. Harvard Business Review, 69(3), 151-164.

Kelley, S. W., Donnelly, J. H., Jr, \& Skinner, S. J. (1990). Customer participation in service production and delivery. Journal of Retailing, 66(3), 315-335.

Kellogg, D. L., \& Nie, W. (1995). A framework for strategic service management. Journal of Operations Management, 13, 323-337.

Lapierre, J. (1997). What does value mean in business-to-business professional services? International Journal of Service Industry Management, 8(5), 377-397.

Larsson, R., \& Bowen, D. E. (1989). Organization and customer: managing design and coordination of services. Academy of Management Review, 14(2), 213-233.

Lengnick-Hall, C. A. (1996). Customer contributions to quality: a different view of the customer-oriented firm. Academy of Management Review, 21(3), 791-824.

Lin, J.-S. C., \& Hsieh, C.-C. (2011). Modeling service friendship and customer compliance in high-contact service relationships. Journal of Service Management, 22(5), 607-631.

Miles, I., Kastrinos, N. I., Flanagan, K., Bilderbeek, R., Den Hertog, P., Huntink, W. et al. (1995). Knowledge-intensive business services. EIMS publication, 15.

Miles, M. B., \& Huberman, A. M. (1994). Qualitative data analysis: an expanded sourcebook. (2nd ed.). London: Sage Publications, Inc.

Mills, P. K., \& Morris, J. H. (1986). Clients as "partial" employees of service organizations: role development in client participation. Academy of Management Review, 11(4), 726-735.

Nätti, S., \& Ojasalo, J. (2008). Loose coupling as an inhibitor of internal customer knowledge transfer: findings from an empirical study in B-to-B professional services. Journal of Business \& Industrial Marketing, 23(3), 213-223.

Nordin, F., \& Kowalkowski, C. (2010). Solutions offerings: a critical review and reconceptualisation. Journal of Service Management, 21(4), 441-459.

Piekkari, R., Plakoyiannaki, E., \& Welch, C. (2010). 'Good' case research in industrial marketing: insights from research practice. Industrial Marketing Management, 39, 109-117.

Ryan, A., Tähtinen, J., Vanharanta, M., \& Mainela, T. (2012). Putting critical realism to work in the study of business relationship processes. Industrial Marketing Management, 41, 300-311.

Santos, J., \& Spring, M. (2013). New service development: managing the dynamic between services and operations resources. International Journal of Operations \& Production Management, 33(7), 800-827.

Selviaridis, K., \& Spring, M. (2010). The dynamics of business service exchanges: insights from logistics outsourcing. Journal of Purchasing and Supply Management, 16(3), 171-184. 
Skjølsvik, T., Løwendahl, B. R., Kvalshaugen, R., \& Fosstenløkken, S. M. (2007). Choosing to learn and learning to choose: strategies for client co-production and knowledge development. California Management Review, 49(3), 110-128.

Stake, R. E. (1995). The art of case study research. London: Sage Publications, Inc.

Stewart, H., Hope, C., \& Muhlemann, A. (1998). Professional service quality: a step beyond other services? Journal of Retailing and Consumer Services, 5(4), 209-222.

Töllner, A., Blut, M., \& Holzmüller, H. H. (2011). What does value mean in business-tobusiness professional services? Industrial Marketing Management, 40, 712-722.

Tuli, K. R., Kohli, A. K., \& Bharadwaj, S. G. (2007). Rethinking customer solutions: from product bundles to relational processes. Journal of Marketing, 71(July), 1-17.

Ulaga, W. (2001). Customer value in business markets: an agenda for inquiry. Industrial Marketing Management, 30, 315-319.

Vargo, S. L. (2008). Customer integration and value creation: paradigmatic traps and perspectives. Journal of Service Research, 11(2), 211-215.

Vargo, S. L., \& Lusch, R. F. (2004). Evolving to a new dominant logic for marketing. Journal of Marketing, 68(1), 1-17.

Windahl, C., \& Lakemond, N. (2006). Developing integrated solutions: The importance of relationships within the network. Industrial Marketing Management, 35, 806-818.

Yim, C. K. B., Chan, K. W., \& Lam, S. S. K. (2012). Do customers and employees enjoy service participation? synergistic effects of seif- and other-efficacy. Journal of Marketing, 76, 121-140.

Yin, R. (2003). Case study research: design and method. (3rd ed.). London: Sage Publications, Inc. 


\section{Appendix A. Protocol of the Interviews}

Company's name:

Interviewee's name:

Interviewee's position:

Company (Familiarization interviews)

1) History of the company

2) Organizational structure and attributions

3) Customers (direct and indirect)

4) Portfolio of products and services (Check main markets and systems sold)

5) Can you guide me through the main activities of delivering a system to a particular customer?

KIBS Delivery process

1) Main activities involved in designing and implementing a system?

2) Common activities across the development of systems for different customers?

3) What is usually customized for one particular customer?

4) What are your key resources, capabilities and knowledge bases?

5) Do you subcontract any part of the process? What? Why?

\section{Customer Participation}

1) How do you exchange information with your customers?

2) What type of information they provide?

3) What are the main problems faced at the interface with customers?

4) How do you handle them? How do you handle changes in customers' requirements?

5) How well do you think you (as a company) meet customers' requirements in each project/job?

Documents / Probes:

1) That's interesting; could you tell me more about that?

2) Could you give me an example?

3) Do you have any document I could see? 
IMM 13-140

\section{Table 1}

Interview data: summary of data collected

\begin{tabular}{|c|c|c|c|}
\hline Case & $\begin{array}{l}\text { Interviewees' } \\
\text { Position }^{\mathrm{a}}\end{array}$ & $\begin{array}{l}\text { Stage of Interaction } \\
\text { with Customer }\end{array}$ & $\begin{array}{l}\text { \#Inter- } \\
\text { views }\end{array}$ \\
\hline \multirow[t]{3}{*}{ Softdev } & $\begin{array}{l}\text { Business Development } \\
\text { Manager (KC) }\end{array}$ & - Service Specification & 3 \\
\hline & Software Developer & $\begin{array}{l}\text { - Technical Specification, Software } \\
\text { Implementation \& Testing }\end{array}$ & 3 \\
\hline & Project Manager & $\begin{array}{l}\text { - Service \& Technical Specification, } \\
\text { Software Implementation \& Testing }\end{array}$ & 1 \\
\hline \multirow[t]{4}{*}{ Audiosystems } & $\begin{array}{l}\text { Administrative Manager } \\
\text { (Owner \& KC) }\end{array}$ & - None & 1 \\
\hline & $\begin{array}{l}\text { Design Engineer } \\
\text { (Owner) }\end{array}$ & $\begin{array}{l}\text { - Service \& Technical Specification, AV } \\
\text { System Support }\end{array}$ & 1 \\
\hline & Project Manager & - Service \& Technical Specification & 1 \\
\hline & Installation Manager & - AV System Installation & 1 \\
\hline \multirow[t]{4}{*}{ CRControls } & $\begin{array}{l}\text { Design Engineer } \\
\text { (Owner \& KC) }\end{array}$ & - Service \& Technical Specification & 2 \\
\hline & $\begin{array}{l}\text { Services Manager } \\
\text { (Owner) }\end{array}$ & $\begin{array}{l}\text { - Service Specification, Building } \\
\text { Controls Support }\end{array}$ & 1 \\
\hline & Project Manager & $\begin{array}{l}\text { - Technical Specification, Building } \\
\text { Controls Installation }\end{array}$ & 1 \\
\hline & Services Analyst & $\begin{array}{l}\text { - Building Controls Installation \& } \\
\text { Support }\end{array}$ & 1 \\
\hline
\end{tabular}

${ }^{\mathrm{a}}$ Note: $\mathrm{KC}=$ Key Contact in the Company 
IMM 13-140

\section{Table 2}

Research constructs: definition of the main concepts used in the study

\begin{tabular}{|c|c|c|}
\hline Construct & Definition & Key References \\
\hline $\begin{array}{l}\text { Customer } \\
\text { Expertise }\end{array}$ & $\begin{array}{l}\text { Knowledge of how the service is to be delivered } \\
\text { and of how to assess its performance. Knowledge } \\
\text { of the offering and its market that results from } \\
\text { different sources }\end{array}$ & $\begin{array}{l}\text { (Auh et al., 2007; Bell et } \\
\text { al., 2005; Bell \& } \\
\text { Eisingerich, 2007) }\end{array}$ \\
\hline $\begin{array}{l}\text { Customer } \\
\text { Role Clarity }\end{array}$ & $\begin{array}{l}\text { Knowledge of what it is expected of them, of the } \\
\text { tasks they have to execute and of their } \\
\text { responsibilities }\end{array}$ & $\begin{array}{l}\text { (Bettencourt et al., 2002; } \\
\text { Dellande et al., 2004; } \\
\text { Lengnick-Hall, 1996) }\end{array}$ \\
\hline $\begin{array}{l}\text { Customer } \\
\text { Motivation }\end{array}$ & $\begin{array}{l}\text { Willingness to exert effort and invest time to } \\
\text { participate in the delivery process }\end{array}$ & $\begin{array}{l}\text { (Eisingerich \& Bell, } \\
\text { 2006) }\end{array}$ \\
\hline $\begin{array}{l}\text { Customer } \\
\text { Participation }\end{array}$ & $\begin{array}{l}\text { Extent to which, during the KIBS delivery } \\
\text { process, customers comply with instructions, share } \\
\text { good quality inputs, support decision-making and } \\
\text { offer constructive feedback }\end{array}$ & $\begin{array}{l}\text { (Bettencourt, 1997; } \\
\text { Dellande et al., 2004; } \\
\text { Eisingerich et al., 2013; } \\
\text { Yim et al., 2012) }\end{array}$ \\
\hline $\begin{array}{l}\text { KIBS } \\
\text { Effectiveness }\end{array}$ & $\begin{array}{l}\text { Extent to which providers delivered the KIBS on } \\
\text { time, as specified and without additional charges }\end{array}$ & (Tuli et al., 2007) \\
\hline $\begin{array}{l}\text { Customer } \\
\text { Education }\end{array}$ & $\begin{array}{l}\text { Actions to teach customers how to execute service } \\
\text { tasks, to guide their decisions, to give them with } \\
\text { skills and ability to interpret information }\end{array}$ & $\begin{array}{l}\text { (Auh et al., 2007; } \\
\text { Eisingerich \& Bell, 2008; } \\
\text { Howcroft et al., 2007) }\end{array}$ \\
\hline $\begin{array}{l}\text { Customer } \\
\text { Socialization }\end{array}$ & $\begin{array}{l}\text { Actions and strategies to share norms, values and } \\
\text { behaviour patterns with customers }\end{array}$ & $\begin{array}{l}\text { (Büttgen et al., 2012; } \\
\text { Kelley et al., 1990) }\end{array}$ \\
\hline $\begin{array}{l}\text { Preventive } \\
\text { Actions }\end{array}$ & $\begin{array}{l}\text { Use of experience, contingencies and assumptions } \\
\text { to fill in gaps left by lack of customer participation } \\
\text { and reduce the need to involve them }\end{array}$ & Data-Driven \\
\hline $\begin{array}{l}\text { Problem } \\
\text { Management }\end{array}$ & $\begin{array}{l}\text { Manage customers concerns, address their } \\
\text { requests and put effort into solving their problems }\end{array}$ & $\begin{array}{l}\text { (Eisingerich \& Bell, } \\
\text { 2006) }\end{array}$ \\
\hline $\begin{array}{l}\text { Providers' } \\
\text { Expertise }\end{array}$ & $\begin{array}{l}\text { Knowledge of a domain, of customers' needs, and } \\
\text { industries, and of specific situations. Problem- } \\
\text { solving and decision-making skills. }\end{array}$ & $\begin{array}{l}\text { (Dane, 2010; Miles et al., } \\
\text { 1995; Nätti \& Ojasalo, } \\
\text { 2008) }\end{array}$ \\
\hline
\end{tabular}


IMM 13-140

\section{Table 3}

Providers' strategies during the KIBS delivery process: actions adopted in each case

\begin{tabular}{|c|c|c|c|}
\hline $\begin{array}{l}\text { Case } \\
\text { (Customer } \\
\text { Participation } \\
\text { Level) }\end{array}$ & $\begin{array}{l}\text { Customer } \\
\text { Education }\end{array}$ & $\begin{array}{l}\text { Preventive } \\
\text { Actions }\end{array}$ & $\begin{array}{l}\text { Problem } \\
\text { Management }\end{array}$ \\
\hline $\begin{array}{l}\text { Softdev } \\
\text { (Higher) }\end{array}$ & $\begin{array}{l}\text { - Meetings during } \\
\text { service delivery } \\
\text { - Use of visual } \\
\text { resources } \\
\text { - Use of consultants }\end{array}$ & $\begin{array}{l}\text { - Alteration of code, if } \\
\text { information is } \\
\text { missing, to avoid } \\
\text { meetings }\end{array}$ & $\begin{array}{l}\text { - Take blame for incorrect } \\
\text { specifications } \\
\text { - Do small alterations for } \\
\text { free } \\
\text { - Advise against unwise } \\
\text { changes } \\
\text { - Not charging for certain } \\
\text { changes } \\
\text { - Explain that alterations } \\
\text { have costs } \\
\text { - Maintain open } \\
\text { communication }\end{array}$ \\
\hline $\begin{array}{l}\text { Audio } \\
\text { Systems } \\
\text { (Lower) }\end{array}$ & - Initial site visit & $\begin{array}{l}\text { - Take photos of site } \\
\text { - No } 2^{\text {nd }} \text { visit when } \\
\text { building is known } \\
\text { - Use of contingencies } \\
\text { - Plan for specification } \\
\text { change }\end{array}$ & $\begin{array}{l}\text { - Take blame for incorrect } \\
\text { specifications } \\
\text { - Do small alterations for } \\
\text { free } \\
\text { - Advise against unwise } \\
\text { changes } \\
\text { - Maintain open } \\
\text { communication }\end{array}$ \\
\hline $\begin{array}{l}\text { CR } \\
\text { Controls } \\
\text { (Lower) }\end{array}$ & $\begin{array}{l}\text { - Use of emails and } \\
\text { phone calls to } \\
\text { clarify } \\
\text { specifications }\end{array}$ & $\begin{array}{l}\text { - Obtain customer- } \\
\text { related information } \\
\text { from other sources } \\
\text { - Complement } \\
\text { specification with } \\
\text { items customers have } \\
\text { not specified } \\
\text { - Plan for specification } \\
\text { change }\end{array}$ & $\begin{array}{l}\text { - Take blame for incorrect } \\
\text { specifications } \\
\text { - Do small alterations for } \\
\text { free } \\
\text { - Advise against unwise } \\
\text { changes } \\
\text { - Provide quotes fast } \\
\text { - Not charging for certain } \\
\text { changes } \\
\text { - Explain that alterations } \\
\text { have costs }\end{array}$ \\
\hline
\end{tabular}




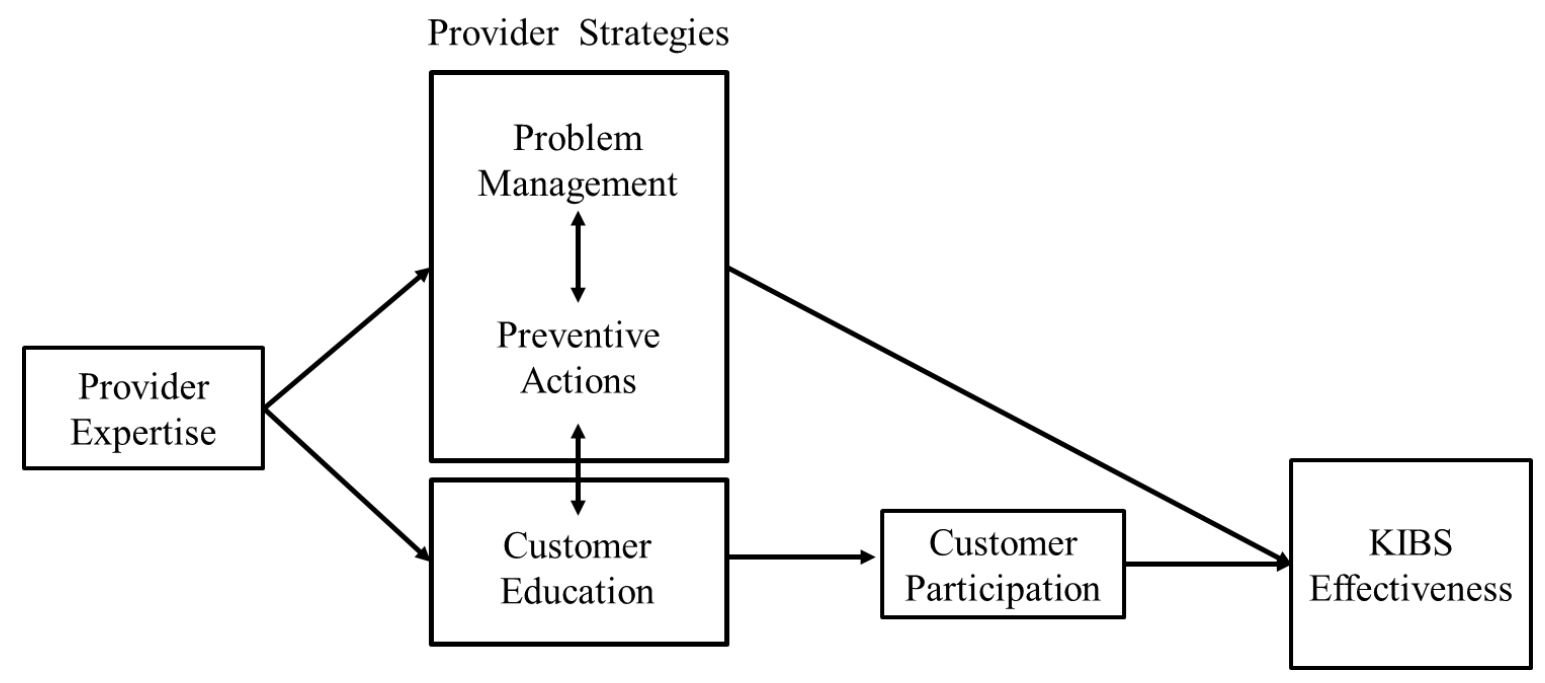

Fig. 1. Providers' strategies: overcoming limited customer participation to increase KIBS effectiveness 